\title{
An Investigation of +2 Level Students' Concepts of Magnetism
}

\author{
S. V. Sharma \\ Regional Institute of Education, Ajmer (Rajasthan)
}

\begin{abstract}
Present study entitled 'An Investigation of +2 Level Students' Concepts of Magnetism' was administered over the students of +2 level learning concepts of magnetism. At the very outset, this study is a pilot study. Research tool was developed in workshop mode comprises of conceptual multiple choice questions. To ensure the validity and reliability of the test each item was scrutinized in a brainstorming session of experts. The test was administered on plus two students' of schools having well equipped facilities and devoted staffs dealing with physics education. Comprehensive analysis of the responses given by the students' indicates a significant gap between the learning outcomes as expected from the curriculum given to the students and their real learning. It is suggested that a carefully planed instructions taking into consideration students' alternative frameworks may help to improve the state of affairs.
\end{abstract}

Keywords: concepts of magnetism and alternative frameworks

\section{Introduction}

A lot of studies have been conducted to know 'How pupils learn Physics'. Many research studies on this subject focus on what may be called as 'preconceptions' and Misconceptions', Pre-concepts are everyday experiences. Common sense theories, array of explanations, beliefs, native world view and interactive knowledge or present status of knowledge by means of which the learners' make their own sense of environment they observe and experience. These have also been referred as alternative frameworks (1-32). Study of exploration of alternative frames of physics amongst the students at various levels has been of much interest during the last few decades (1-32). This is especially important from the view of meaningful and effective teaching learning. For a prior knowledge of the alternative frames amongst the students can be the basis for generating discussion and planning of strategy to help the students acquire the correct concepts and also make them think in a scientific way. Since concepts have been found to be resistant to change, it is all the more important they are identified and suitable strategies are employed in the classroom situation. Physics is taught as independent discipline at plus two (+2) level. The teachers to transfer the curriculum of physics utilize different model of transactions. Students accept some of the principles/theories/concepts by modifying their existing mini theories invalidate and reject others. But every time a new mental map is formed. If the conventional principles/concepts cannot be fitted into their mental structure even by its continuous reinforcement, they cram it and ultimately lose interest in learning physics, thus the main responsibility of the teachers is to accommodate the accepted physics with the structure of the students and thus to squeeze out the wrongly constructed knowledge which would otherwise be a great barrier to learning. Therefore for imparting meaningful and effective learning the teacher is very much expected to have an insight of the existing mental structures of the students. Keeping afore said in mind, present study entitled 'An Investigation of +2 Level Students' Concepts of Magnetism' has been carried out (27) with following objectives:

- To examine the students' alternative frames about the concepts of physics, in particular, magnetism at +2 level.
- To locate the origin of the alternative frames.

- To suggest ways and means for eradicating the alternative frames.

- Following assumptions have been made for conducting the present study:

- Students already have knowledge of physics, in particular concepts of magnetism, before coming to the classroom Most probably this knowledge may not be consistent with established principles /laws/theories.

- Students are in the possession of different mini-theories. Students keep on changing and proposing new minitheories on encountering with new situations.

- Mental structures of students are highly influenced by the peer group and other members of society.

- This situation of possession of theories by students is advantageous to the teacher, as she/he need not start from the vacuum. It facilitates in accepting, rejecting or modifying the knowledge structured in the students' mind.

\section{Design, Sample and Process}

At the very outset, present study is a pilot study related with the concepts of magnetism and administered over 267 students of plus two level of Ajmer district. Research tool (27) comprises of conceptual multiple choice questions was developed in workshop mode (Appendix-1). Multiplechoice questions have four options, one of them is correct answer and other three are suspected frames. To ensure the validity and reliability of the test each item was scrutinized in a brainstorming session of experts. The test was then administered on plus two students of schools having well equipped facilities and devoted staffs dealing with physics education. Students were directed to select correct option from the multiple-choice options. They were advised to write supportive reasons for selecting the options. No time limit was set to respond the questionnaire (Research Tool). However, 50 minutes duration was sufficient for students to answer the questionnaire fully. During the analysis the sex of the students was ignored. Comprehensive analysis of the responses of the students was done.

\section{Volume 6 Issue 12, December 2017}




\section{Analysis of the Students' Responses}

Response to each question of the questionnaire was analyzed and discussed in order to understand the reasons of options favoured by the students. Graphical representations of responses of students are shown in Fig.1.

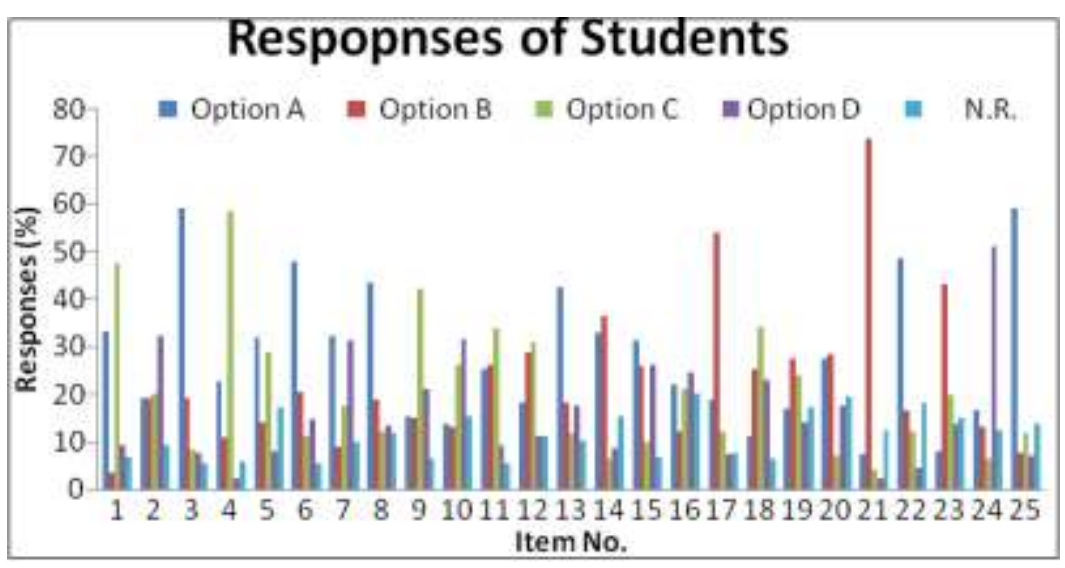

Figure 1: Graphical representation of Students' Responses

Graphical representation of percentages of students' responses in terms of Correct Frames and Alternative Frames are shown in Fig. 2. During the analysis of responses no separate account was kept for male and female students. It is worthwhile to note from the above analysis of the students' responses that there is a section of students who do carry alternative frames about the basic concepts of magnetism (item nos.1-2, 5-16, 18-20, 22-23). It can also be seen from the analysis of the responses given by students that their views for opting an option for a particular question are not concrete. This may be attributed to the existence of alternative frameworks in their minds.

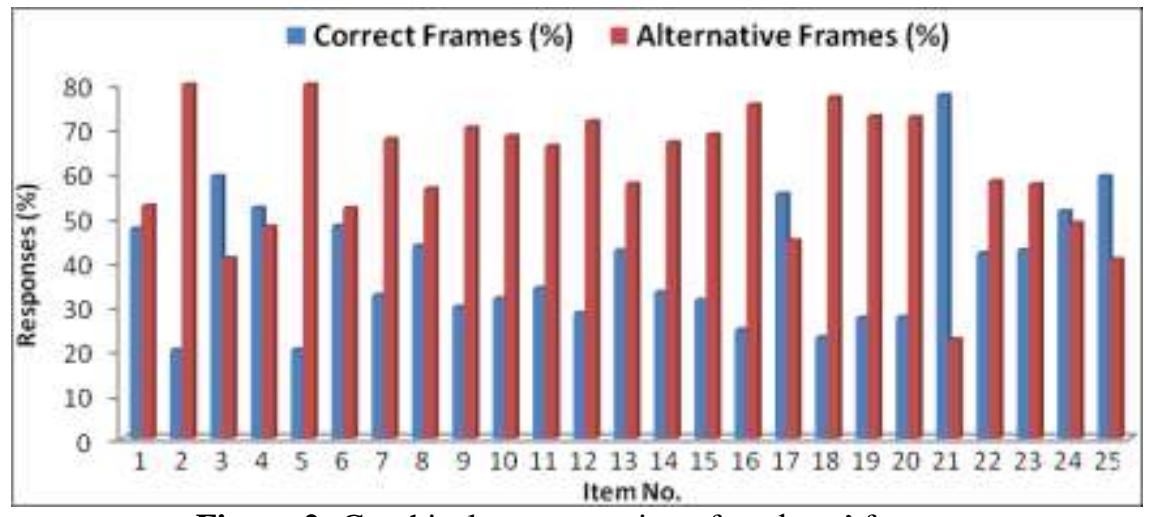

Figure 2: Graphical representation of students' frames

\section{Students' Frameworks}

Analysis of the responses indicates the following students' frameworks about the basic concepts of magnetism:

a) Origin of magnetism in materials is due to

- Presence of free electrons in the materials.

- Presence of positive ions in the materials.

- Orbital motion and spin of the electrons.

- Only due to orbital motion of the electrons.

b) Magnetic moment of a magnet is

- Due to free electrons.

- Independent of temperature.

- Due to random motion of electron.

c) Magnetic moment of a current carrying loop

- depends upon length and not area.

- depends on area.

- changes with change in cross-section area
- not depends on shape.

d) Direction of Induced current

- Can be found using Lenz law.

- Can be found using right hand thumb rule.

- Is always opposite to the cause.

e) Motion of a charge particle in magnetic field will

- Be helical

- Be accelerated

- Be circular

- Not be affected.

f) When a steady current flows through a wire, direction of induced current

- Be clockwise

- Be anti-clockwise

- No current will be induced

- Depends on current and the distance

Volume 6 Issue 12, December 2017 www.ijsr.net 


\section{International Journal of Science and Research (IJSR) \\ ISSN (Online): 2319-7064}

Index Copernicus Value (2016): 79.57 | Impact Factor (2015): 6.391

g) Acceleration of a bar magnet

- Be equal to gravitational acceleration

- Be less than gravitational acceleration

- Depend on the magnetic nature

- Depend on mass of the bar magnet

h) Pole Strength

- Does not depend upon the distance between the poles.

- Depends upon the distance between the poles.

- Does not depend upon size and shape of the pole.

- Depends upon size and shape of the pole.

i) Magnetic lines of force inside a bar magnet

- Are from north to south

- Are from south to north

- Do not exist

- Are closed loops within the bar magnet

j) An e.m.f. is produced in a coil can't be due to the coil

- Being in a time varying magnetic field.

- Moving in a time varying magnetic field.

- Moving in a constant magnetic field.

- Is stationary in external specially varying magnetic field.

k) Mutual Inductance

- Depends upon distance between the coils.

- Does not depend upon distance between the coils.

- Depends upon number of turn and current in the coil.

- Does not depend upon number of turn and current in the coil

l) If two lines of magnetic force were intersecting each other it would have meant

- Magnitude of the two magnetic fields are different at the point of intersection

- Direction of two magnetic fields are different at the point of intersection

- Both magnitude and direction of magnetic field strengths are different at the

- Point of intersection.

m) Magnetic field lines

- Can never emanate from a point.

- Are not confined within a toroid.

- Move in a circular path.

- Always forms closed loop.

n) Effect of heating a magnetic will

- Weaken its magnetic strength

- Enhance pole strengths

- Change its polarity

- Not change its magnetic strength

- Change the alignment of domains.

\section{Implications of the Study}

Investigations into students' ideas pertaining to basic concepts of magnetism were limited to 267 students and study was administered over the students studying at +2 level. Therefore the results of the study can not be generalised to other parts of the country. Concepts studied were origin of magnetism, magnetic moment of a magnet, field lines of a magnet, pole strength of a bar magnet, magnetic moment of a current carrying loop, direction of induced current, motion of magnet in magnetic field, magnetic field intensity, work done by magnetic force, motion of change particle in magnetic field, direction of induced current, Motion of bar magnet in magnetic field, pole identification, direction of Induced current, pole strength, magnetic lines of force, electro motive force, effect of magnetic field on metallic disc, pole Identification, pines of magnetic force, magnetic field lines and effect of heating on a magnetic strength. Responses were obtained using a questionnaire having multiple choice questions to be answered giving reasoning. The responses indicated that there is a significant difference and a wide gap between the learning outcomes as expected from the curriculum given to the students and their real learning at +2 level. To close the gap between what we teach and what is learned, following suggestions are given:

Students may be asked to design the magnetic devices/experiments themselves, make predictions, observe and then explain. Interaction amongst the students may be encouraged so that their ideas are flushed out and mental conflict does take place before any final formation of the concept related with the magnetism.

Students should be made familiar about the process skills of physics. It has been observed that the students in spite of having knowledge about the basic concepts of magnetism, they are not able to apply them in unknown situation. It is, therefore, necessary that the students are made to perform any activity or experiment systematically and are trained in process skills which they can make use of while drawing inferences related with the basic concepts of magnetism and magnetic devices/phenomena/laws. It is suggested that corrective measures are necessary to be taken by the teachers to rectify students' alternative frames related with the basic concepts of magnetism. Change in the style of teaching, methods of teaching in the class, performing experiments \& demonstrations, solving the problems for constructing and reconstructing the ideas are seem to be paid focussed attention.

As teachers/ teacher educators, challenge is to match the needs of the students to a world that is changing with rapid pace. To meet this challenge, there is a need to become strategic learners. It is, therefore, suggested that teachers should act as strategic learners (active researchers and developers of innovations and new directions) by deliberately expanding perspectives and updating their approaches related with teaching learning the basic concepts of magnetism. The curriculum for school education should emphasise on 'Higher Order Thinking Skills' in its rationale, stating that thinking skills are essential in 'learning how to learn'. Hence there is a need of well organized teachinglearning strategies for classrooms that invites and supports 'Teaching for Thinking' and 'Quality Learning'. Accordingly, staffs need to be specially trained and methods need to be introduced into the curriculum for teaching the skills of thinking and associated cognitive and metacognitive strategies. Also innovative instructional materials and strategies (i.e. thinking lessons, thinking tools, resource 


\section{International Journal of Science and Research (IJSR) \\ ISSN (Online): 2319-7064 \\ Index Copernicus Value (2016): 79.57 | Impact Factor (2015): 6.391}

materials i.e. print, video and audio) for teachers to teach different thinking skills are suggested in present time-frame of school to achieve the mission

\section{Acknowledgements}

Author is thankful to Prof. H.C. Jain, Prof. P.C. Agarwal, Dr. K.C. Sharma, Dr. V.P. Arya, Dr. R. Pratap, Mr. S. Prakash, Dr. T. K. Tyagi, Mr. S.Tomar and Ms. P. Chaturvedi for their participation in the workshops for research tool development/ validation.

\section{References}

[1] Bark M. (2004) Research in Science and Technology Education 22, 171.

[2] Borghi L et al (2005) Physics Education 40 (3) 267.

[3] Bryce T. and Macmillan K. (2005) 27 (6) 737.

[4] Carvalho P. S. and Sousa A. S. (2005) Physics Education 40 (3) 257.

[5] Colin. P., Chauvet F and Viennot L. (2002) Int. J. Sci. Edu. 24 (3) 313.

[6] Driver R. (1981) Euro. J. Science Education 3, 93.

[7] Driver, R. H. (1981) Eur. J. Science Education 3(1) 93101.

[8] Fu, Y. (1990), Students' Understanding of the Magnetic Field of a Circular Current Loop, Phys Edu., 25, 32527.

[9] Gilbert J. K., Osborne J. and Fen sham P. J. (1982), Science Education 66, 623.

[10] Good, R. G. (1991), Editorial, Journal of Research in Science Teaching 28(5).

[11] Hestenes D. and Wells M. (1992), The Physics Teacher 30, 159. Saxena A. B. (1991) Int J Sci. Edu. 13 (3) 283.

[12] Saxena A. B. (1996) Physics Education 194.

[13] Savinainen A and Scatt P., (2002) Physics Education 37 (1) 45 .

[14] Jain H. C., Sharma S.V., Prabha S. and Arya V.P.(2003), Project report, NCERT, RIE Ajmer.
[15] Khaparde R. B. and Pradhan H. C. (2002) Physics Education 229.

[16] Pinto R. and Ametller (2002) Int. J. Sci. Edu. 24 (3) 333.

[17] Sharma S. V., Physics Education, 25, 79-91(2008).

[18] Sharma S. V. and Sharma K.C., Physics Education (UK) 42, 516-521 (2007).

[19] Sharma S. V., IAPT Bulletin- Monthly Journal, 168175(2011).

[20] Sharma S. V., J. of Golden Research Thoughts 3-3, 19(2013).

[21] Sharma S. V. (2014) International Journal of Science and Research 3 (7), 2162-2171.

[22] Sharma S. V., et al, (2015) The Primary Teacher, XXXX (1) 88-98.

[23] Sharma S. V. (2015) International Multidisciplinary Research Journal Golden Research Thoughts, 4 (8) 115 .

[24] Sharma S. V. (2015) International Journal of Science and Research 4 (2) 105-112.

[25] Sharma S. V., Indian Streams Research Journal (International Multidisciplinary Research Journal) (6) 11 44-53 (2016).

[26] Sharma S. V., (2017) Physics Education: Alternative Frames of Physics, Manakin Press, (ISBN 978-9384370-02-2) New Delhi.

[27] Sharma S. V. and Arya V.P. (2017) Project Report, NCERT, RIE Ajmer.

[28] Sharma S. V. and Arya V.P. (2017) Presented Paper in National Seminar on Science Education, RIE Ajmer.

[29] Thacker, B., Kim, E., Trefez, K. \& Lea, S. M. (1994), Comparing Problem Solving Performance of Physics Students' in Enquiry Based and Traditional Introductory Physics Courses, Am. J. Phys. 62, 627-33.

[30] Watson J.R. (2004) Int. J. Science Education 26, 57.

[31] Wickman P. O. and Cox A. J. (2002) Int. J. Science Education 24, 465

[32] Willian F. J. III (2002) Physics Education 37.

\section{Appendix-1}

\section{Questionnaire}

Q.1 The primary origin of magnetism in materials is due to
(a) presence of free electrons in the materials
(b) presence of positive ions in the materials
(c) orbital motion and spin of the electrons
(d) only due to orbital motion of the electrons

Q.2 A permanent magnet placed at room temperature. Which one of the following statements is true:

(a) magnetic moment of each molecule is zero.

(b) the individual molecules have non-zero magnetic moment which is all perfectly aligned.

(c) domains are partially aligned

(d) domains are all perfectly aligned

Q.3 Magnetic field lines are shown in Fig. 1 (a) \& (b) which one of the following options is correct regarding magnetic field strength? 


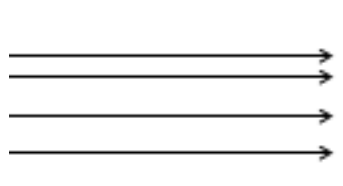

Fig. 1 (a)

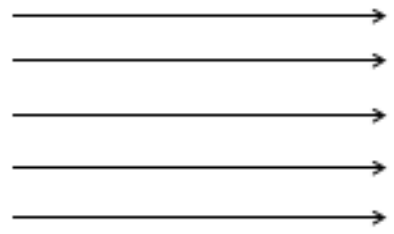

Fig.1 (b)

(a) magnetic field strength is more in Fig. 1(a)

(b) magnetic field strength is more in Fig. 1(b)

(c) magnetic field strength is same in both the Fig. 1(a) \& (b)

(d) additional information is required to respond it.

Q.4 When a bar magnet [Fig. 2 (a)] is cut in two equal pieces [Fig. 2(b)] as shown below:
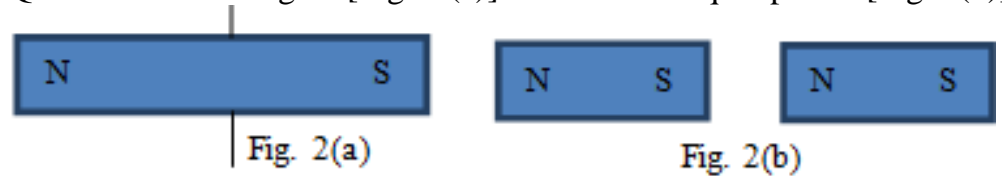

Fig. 2(b)

Then the pole strength of new magnet
(a) becomes half
(b) becomes double
(c) remains same
(d) cannot be predicted

Q.5 The magnetic moment of a square shaped current carrying wire is $\mathrm{m}$. If this wire is converted into circular shaped loop. Then the magnetic moment of circular shaped loop
(a) remains same
(b) changes
(c) becomes $\pi$ times of magnetic moment of square shaped wire.
(d) additional information is required to respond it.

Q.6 Four options [Fig.3(a) - (d)] with respect to relative motion between a bar magnet and a circular coil are shown below:

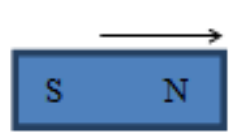

(a)

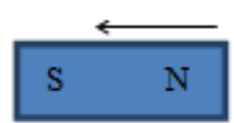

(c)
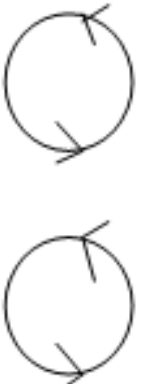

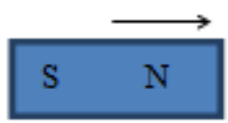

(b)

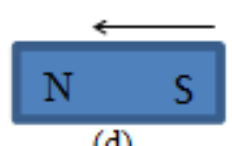

(d)<smiles>CC12CCCCC(C)(CCCC1)C2</smiles><smiles>CC12CCCCC(C)(CCCC1)C2</smiles>

Figure 3

Which one of the above options is correct regarding the direction of induced current in the coil?

Q.7 A bar magnet is kept in a uniform magnetic field (Fig. 4). If a small angular displacement is given to the bar magnet fixed at the centre $(\mathrm{O})$ and energy conservation law hold well then magnet will

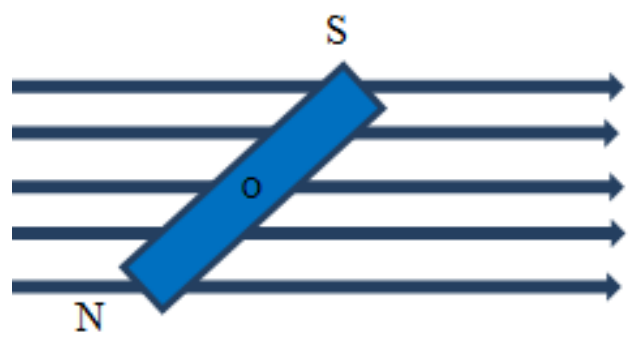

Fig. 4

(a) execute simple harmonic motion

(b) execute linear motion

(c) set perpendicular to the magnetic field

Volume 6 Issue 12, December 2017

\author{
www.ijsr.net
}

Licensed Under Creative Commons Attribution CC BY 


\title{
International Journal of Science and Research (IJSR) \\ ISSN (Online): 2319-7064 \\ Index Copernicus Value (2016): 79.57 | Impact Factor (2015): 6.391
}

(d) be stable when $\mathrm{N}$ end of the bar magnet is towards $\mathrm{S}$ of the magnetic field \& $\mathrm{S}$ end of the bar magnet is towards $\mathrm{N}$ of the magnetic field.

Q.8 Consider a bar magnet $\left(\mathrm{M}_{1}\right)$ is fixed on the top of the table. Taka a point near the magnet $(\mathrm{M})$. Another magnet $\left(\mathrm{M}_{2}\right)$ is

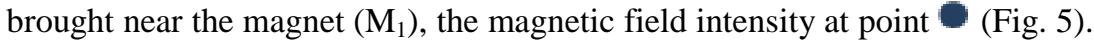

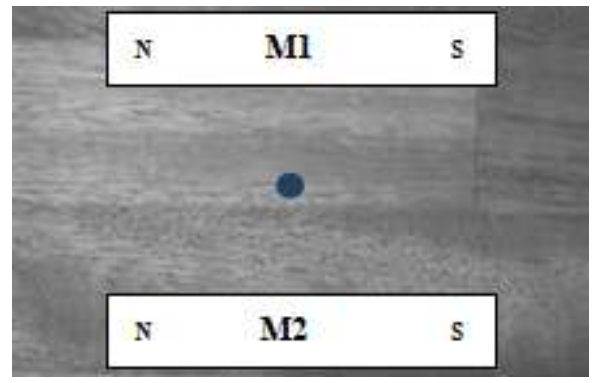

Fig. 5

(a) increases when magnet $M_{2}$ is brought near the magnet $M_{1}$

(b) decreases when magnet $\mathbf{M}_{2}$ is brought near the magnet $\mathbf{M}_{1}$

(c) remains unaffected

(d) turns to zero

Q.9 The net work done by a magnetic force on a moving charge will always
(a) positive (b) negative
(c) zero (d) depend on situation

Q.10 A charged particle is projected with a uniform velocity along the axis of a current carrying long solenoid. Which one of the following statements is true?

(a) the particle will be accelerated along the axis

(b) the path of particle will be circular about the axis

(c) the particle will experience a force at an angle to the axis and hence execute helical path

(d) the particle will continue to move with uniform velocity.

Q.11 A steady current is flowing through a wire $A B$ then the direction of induced current (I) in the coil (Fig. 6)

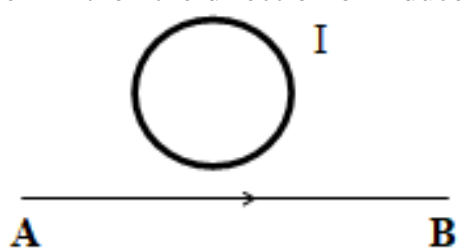

Fig. 6
(a) be clockwise
(b) be anti-clockwise
(c) no current will be induced in the coil
(d) depends on current and the distance between coil and wire AB

Q.12 A solenoid made of a metal wire is placed vertically on a table and a bar magnet falls along its axis then acceleration of bar magnet will:
(a) be equal to gravitational acceleration
(b) be less then gravitational acceleration
(c) depend on the magnetic nature of the metallic wire of the solenoid
(d) depend on mass of the bar magnet

Q.13 Consider the circuit shown in Fig. 7.

Volume 6 Issue 12, December 2017

\author{
www.ijsr.net
}

Licensed Under Creative Commons Attribution CC BY 


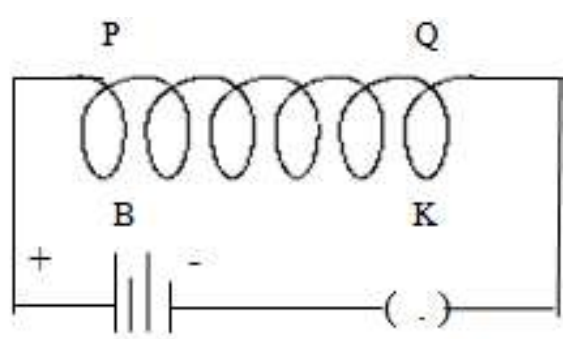

Fig. 7

When a current passes in the solenoid then the ends $\mathrm{P}$ and $\mathrm{Q}$ of the solenoid behave like

(a) P end as $\mathrm{S}$ pole \& $\mathrm{Q}$ end as N Pole

(b) P end as N pole \& $\mathrm{Q}$ end as N Pole

(c) P and Q ends of the solenoid will not behave as $\mathrm{N}$ and $\mathrm{S}$ poles of a magnet

(d) additional information is required to predict about behaviour of $\mathrm{P}$ and $\mathrm{Q}$ ends of the solenoid.

Q.14 When a magnet is moved towards a coil connected to a Galvanometer (G) as shown in the Fig. 8.

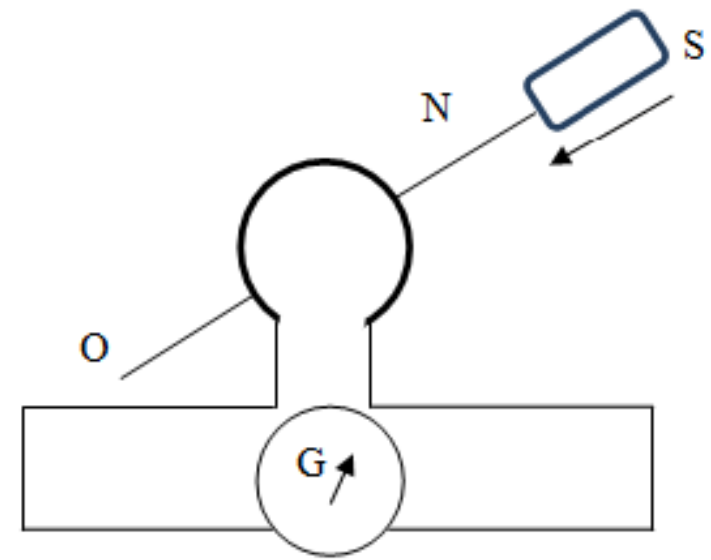

Fig. 8

The direction of induced current (I) in the coil with respect to an observer (O)
(a) will be like clockwise
(b) will be like anticlockwise
(c) no current will be induced in the coil
(d) eddy current will be induced in the coil Give reason for selecting the option.

Q.15 Two poles of a magnet are shown below in the Fig. 9:

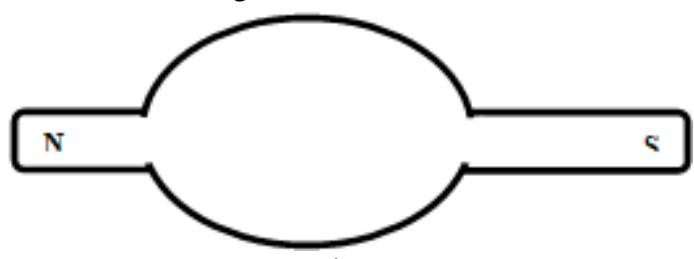

Fig.9

Which one of the following statements is correct?
(a) both poles have equal strengths
(b) the two poles have unequal strengths
(c) the relative pole strengths of $\mathrm{N}$ and $\mathrm{S}$ cannot be predicted
(d) the pole strength does not depend upon its shape and size

Q.16 Inductance in electricity is analogous to
(a) impulse (b) momentum
(c) torque $(\mathrm{d})$ inertia

Q.17 Magnetic lines of force inside a bar magnet:
(a) are from north to south
(b) are from south to north
(c) do not exist
(d) are closed loops within the bar magnet

Volume 6 Issue 12, December 2017

\author{
www.ijsr.net
}

Licensed Under Creative Commons Attribution CC BY 


\title{
International Journal of Science and Research (IJSR) \\ ISSN (Online): 2319-7064 \\ Index Copernicus Value (2016): 79.57 | Impact Factor (2015): 6.391
}

Q.18 An e.m.f. is produced in a coil, which is not connected to an external voltage source. This cannot be due to
(a) the coil being in a time varying magnetic field.
(b) the coil moving in a time varying magnetic field.
(c) the coil moving in a constant magnetic field.
(d) the coil is stationary in external specially varying magnetic field, which does not change with time.

Q.19 Consider a light metallic disc is kept above a solenoid with its centre coinciding with the axis of the solenoid, if the key is suddenly closed momentarily then what will happen to the metallic disc?
(a) the metallic disc will fall down
(b) the metallic disc will experience a momentarily jumps up
(c) the metallic disc will remain unaffected
(d) the metallic disc will oscillate up and down

Q.20 The mutual inductance $\mathrm{M}_{12}$ of coil 1 with respect to coil 2
(a) increases when they are brought near
(b) depends on the current passing through the coils.
(c) increases when one of them is rotated about an axis
(d) is not the same as $\mathbf{M}_{21}$ of coil 2 with respect to coil 1

Q.21 A bar magnet is broken into two pieces such that one piece is bigger and the other one is smaller. Which one of the following options is correct?
(a) bigger piece will have north pole and smaller south pole
(b) both the pieces will have both the poles
(c) both the pieces will not have any pole
(d) bigger piece will have both the poles and the smaller piece will not have any pole

Q.22 Which of the following correspondence is correct?
(a) permittivity corresponds to electric field and permeability corresponds to magnetic field.
(b) permittivity corresponds to magnetic field and permeability corresponds to electric field
(c) both permittivity and permeability corresponds to electric field
(d) both permittivity and permeability corresponds to magnetic field.

Q.23 If two lines of magnetic force were intersecting each other it would have meant
(a) magnitude of the two magnetic fields are different at the point of intersection
(b) direction of two magnetic fields are different at the point of intersection
(c) both magnitude and direction of magnetic field strengths are different at the point of intersection
(d) no conclusion can be drawn.

Q.24 Which one of the following statements is true?
(a) magnetic field lines can never emanate from a point
(b) magnetic field lines are not confined within a toroid.
(c) magnetic field lines due to a solenoid at its ends \& outside cannot be completely straight \& confine
(d) there are magnetic field lines outside and inside a bar magnet

Q.25 The effect of heating a magnet will
(a) weaken its magnetic strength
(b) enhance pole strengths
(c) change its polarity
(d) will not change its magnetic strength

Volume 6 Issue 12, December 2017

\author{
www.ijsr.net
}

Licensed Under Creative Commons Attribution CC BY 